\title{
Efficacy of doppler velocimetry of the umbilical artery in the defined high-risk groups to determine the fetal outcome
}

\author{
Maneesha R. Suryavanshi ${ }^{1}$, Shriraj S. Katakdhond ${ }^{2 *}$
}

\begin{abstract}
${ }^{1}$ Department of Obstetrics and Gynecology, YCM Hospital, Pimpri, Pune, Maharashtra, India
${ }^{2}$ Department of Obstetrics and Gynecology, Dr. DY Patil Medical College, Hospital and Research Centre, Pimpri, Pune, Maharashtra, India
\end{abstract}

Received: 03 April 2019

Accepted: 13 April 2019

*Correspondence:

Dr. Shriraj S. Katakdhond,

E-mail: dr.shrirajsk@gmail.com

Copyright: (c) the author(s), publisher and licensee Medip Academy. This is an open-access article distributed under the terms of the Creative Commons Attribution Non-Commercial License, which permits unrestricted non-commercial use, distribution, and reproduction in any medium, provided the original work is properly cited.

\begin{abstract}
Background: Doppler ultrasound provides a non-invasive method of studying the status of various blood vessels. It provides a spectrum analysis of the velocities of moving red blood cells. Doppler sonography can provide useful information in a variety of gynecological and obstetric conditions. In obstetrics, Doppler velocimetry of the uteroplacental and fetoplacental circulation can be used to further investigate complications of pregnancy such as fetal growth restriction, other forms of fetal distress that result from fetal hypoxemia or asphyxia.

Methods: In a prospective observational study, 93 pregnancies fitting in the criteria for high risk were evaluated by doppler velocimetry between $28-40$ weeks of gestation. The flow velocity time wave forms were examined and quantitated by use of systolic/diastolic (S/D) ratio, resistance index (RI), pulsatility index (PI) values. The outcome of pregnancy was noted.

Results: Fetuses with abnormal velocimetry are at higher risk with regard to birth weight, Apgar score, fetal distress, need of cesarean section, need of NICU admission. The patients with absent end-diastolic flow (AEDF)/reversal of end-diastolic flow (REDF) had poor perinatal outcome. Positive predictive value for small for gestational age (SGA) and fetal distress was $75 \%$ and $60 \%$ respectively. $23.8 \%$ babies needed to be kept in neonatal intensive care unit (NICU).

Conclusions: Doppler velocimetry can be useful prenatal test for the patients of hypertensive disorder of pregnancy and IUGR. Abnormal doppler waveform changes indicate adverse perinatal outcome. Appropriate and timely interventions guided by doppler study help to reduce perinatal morbidity and mortality.
\end{abstract}

Keywords: Doppler velocimetry, Perinatal outcome, Umbilical artery

\section{INTRODUCTION}

Doppler ultrasound provides a non-invasive method of studying the status of various blood vessels. It provides a spectrum analysis of the velocities of moving red blood cells.

To achieve a normal pregnancy outcome, there should be good utero-placental circulation. In normal pregnancy, there is low resistance and high uteroplacental blood flow, while in hypertensive pregnancy and with fetal growth restriction, the blood flow in umbilical and uterine artery decreases. ${ }^{1}$ Thus, it is essential to asses fetal circulation for better understanding of the pathophysiology of a wide range of pathological pregnancies and their clinical management. Assessment of placental circulation by doppler velocimetry become a vital tool in screening for impaired placentation and its complications 
like pre-eclampsia, intrauterine growth restriction and perinatal death. The doppler abnormalities in umbilical and uterine artery have been documented in pregnancies complicated by hypertension and fetal growth restriction. $^{2,3}$

Umbilical artery doppler waveforms provide an estimate of downstream placental vascular resistance and placental blood flow. Abnormalities in umbilical artery waveforms are progressive with reduction, loss and finally reversal of diastolic flow. Reversed flow is associated with increased risk of fetal acidosis and high incidence of perinatal morbidity and mortality.

The purpose of present study was to study efficacy of doppler velocimetry of the umbilical artery in the defined high risk groups to determine fetal outcome.

\section{METHODS}

The period of present study extended from September 2012 to August 2013. Informed consent was obtained from each woman studied.

Doppler study of umbilical artery was carried out in 93 patients with defined high-risk pregnancy at tertiary care hospital, Pimpri, Pune, Maharashtra, India.

\section{Inclusion criteria}

- $\quad$ Singleton pregnancy

- 28 weeks to 40 weeks

- Vertex presentation

- Defined high risk group included in the study

- Gestational hypertension

- Preeclampsia

- Chronic hypertension with superimposed preeclampsia

- $\quad$ Suspected IUGR

\section{Exclusion criteria}

- Multifetal pregnancy

- Diabetes in pregnancy

- Anaemia

- Congenital malformed fetus

- Previous cesarean section

- Previous history of myomectomy

\section{Procedure}

The pregnant women assumed a supine slightly tilted left lateral position. A coupling jelly was placed upon the abdomen and the doppler probe was placed over the fetus.

Umbilical artery in the cord was recognized by the characteristics shape of the velocity wave forms on the oscilloscope and sound. The peak systolic velocity and end diastolic velocity was measured. From this systolic/diastolic (S/D) ratio, resistance index (RI), pulsatility index (PI), absence or reversal of end diastolic flow (AEDF/REDF) were recorded.

The patients with S/D ratio equal or more than 3, absent or reversed end diastolic flow (AEDF/REDF) were admitted for further evaluation. The results were communicated to the patients. These patients were followed up till delivery.

Steroids were administered intramuscular as two doses of $12 \mathrm{mg}$ of betamethasone twenty-four hours apart to patients between 28 to 34 weeks of gestation for fetal lung maturity.

Data collected includes diagnosis of high-risk pregnancy, gestational age at delivery, elective or emergency cesarean section (CS), birth weight, Apgar scores, and need of neonatal intensive care unit (NICU).

The perinatal outcome was noted and compared with results of the doppler velocimetry.

Data was analyzed using Epi info software. Quantitative variable expressed in terms of means and standard deviation while qualitative variable described in terms of frequency and percentage.

\section{RESULTS}

The purpose of present study was to study efficacy of doppler velocimetry of the umbilical artery in the defined high-risk groups to determine the fetal outcome.

Total 93 pregnancies were evaluated by doppler velocimetry.

Age

In present study, $41.9 \%$ patients were between 21-25 years of age while $22.5 \%$ were from 26-30 years of age, $12.8 \%$ cases were elderly gravida (Table 1 ).

Table 1: Age distribution in present study.

\begin{tabular}{|ll|}
\hline Age (years) & Number of patients \\
\hline $16-20$ & $12(12.90 \%)$ \\
\hline $21-25$ & $39(41.93 \%)$ \\
\hline $26-30$ & $21(22.58 \%)$ \\
\hline $31-35$ & $09(09.67 \%)$ \\
\hline $36-40$ & $09(09.67 \%)$ \\
\hline $41-45$ & $03(03.22 \%)$ \\
\hline Total & 93 \\
\hline
\end{tabular}

\section{Parity}

In present study, $35.48 \%$ cases were primigravidas and $64.51 \%$ cases were multigravidas (Table 2 ). 
Table 2: Maternal characteristics in present study.

\begin{tabular}{|lll|}
\hline Maternal characteristics & No. of patients & $\%$ \\
\hline Parity & 33 & $35.48 \%$ \\
\hline Primigravida & 30 & $64.51 \%$ \\
\hline Multigravida & 60 & $16.10 \%$ \\
\hline Defined high risk group & & $32.25 \%$ \\
\hline Gestational hypertension & 15 & $12.90 \%$ \\
\hline Pre-eclampsia & 30 & $38.70 \%$ \\
\hline $\begin{array}{l}\text { Chronic hypertension } \\
\text { with superimposed } \\
\text { pre-eclampsia }\end{array}$ & 12 & \\
\hline IUGR & 36 & \\
\hline
\end{tabular}

\section{Defined high risk group}

Among 93 cases, 57 patients had hypertensive disorder of pregnancy and 36 patients had intrauterine growth restriction.
In hypertensive disorder group, 15 patients had gestational hypertension, 30 patients had pre-eclampsia and 12 patients had chronic hypertension superimposed pre-eclampsia (Table 2).

\section{S/D ratio (systolic/diastolic ratio)}

S/D ratio in present study ranged between $2.03 \pm 0.4$ to 6.0 .

Doppler waveform of the umbilical artery was considered abnormal if $\mathrm{S} / \mathrm{D}$ ratio was equal to or more than 3 , diastolic flow was absent /reversed.

The abnormal S/D values varied from $3.52 \pm 0.34$ to 6.0 (Table 3).

Abnormal umbilical Doppler velocimetry was seen in $38.70 \%$ of patients in present study (Table 4).

Table 3: Normal and abnormal values of S/D ratio, RI, and PI of umbilical artery in present study.

\begin{tabular}{|c|c|c|c|c|c|c|}
\hline \multirow{3}{*}{ Gestational age in weeks } & \multicolumn{6}{|c|}{ Umbilical Artery } \\
\hline & \multicolumn{2}{|c|}{ S/D } & \multicolumn{2}{|l|}{ RI } & \multicolumn{2}{|l|}{ PI } \\
\hline & Normal & Abnormal & Normal & Abnormal & Normal & Abnormal \\
\hline $28-31$ & $2.27 \pm 0.36$ & $3.52 \pm 0.34$ & $0.5 \pm 0.1$ & $0.72 \pm 0.08$ & $0.73 \pm 0.07$ & $1.13 \pm 0.07$ \\
\hline $32-36$ & $2.03 \pm 0.4$ & $3.92 \pm 0.52$ & $0.47 \pm 0.15$ & $0.72 \pm 0.08$ & $0.58 \pm 0.13$ & $1.19 \pm 0.1$ \\
\hline $37-40$ & $2.6 \pm 0.2$ & 6.0 & $0.45 \pm 0.05$ & 0.8 & $0.55 \pm 0.02$ & 1.42 \\
\hline
\end{tabular}

Table 4: Number of patients with normal and abnormal indices of umbilical artery in present study.

\begin{tabular}{|llll|}
\hline Site & Umbilical artery & & PI \\
\hline Indices & S/D ratio & RI & $54(58.07 \%)$ \\
\hline No. of patients with normal values & $57(51.30 \%)$ & $60(54.52 \%)$ & $39(41.93 \%)$ \\
\hline
\end{tabular}

\section{Resistance index (RI)}

In present study, normal RI index ranged from $0.45 \pm 0.05$ to $0.5 \pm 0.1$ (Table 3).

Resistance Index more than 0.7 was considered abnormal. Abnormal RI value ranged from 0.72 to 0.8 (Table 3).

\section{Pulsatility index (PI)}

In this study, normal PI of the umbilical artery range from $0.55 \pm 0.02$ to $0.73 \pm 0.07$ (Table 3 ).

PI more than 1 was considered abnormal in present study. Thirty-nine patients had abnormal PI (Table 4).

\section{Fetal outcome}

Twenty-one patients with $\mathrm{S} / \mathrm{D}$ ratio more than 3 in hypertensive group, delivered at mean gestational age of $36.4 \pm 2.3$ weeks with mean birth weight $2275 \pm 247$ grams (Table 5).

Six patients in hypertensive disorder of pregnancy group had AEDF/REDF, mean gestational age at delivery was $32.5 \pm 0.6$ weeks with mean birth weight of $1170 \pm 381$ grams.

In intrauterine restriction group, twenty-seven patients with normal doppler study delivered at mean gestation age of $37 \pm 1.1$ weeks, while six patients with $\mathrm{S} / \mathrm{D}$ ratio more than 3 delivered at mean gestational age of $36.0 \pm 2.2$ weeks. 
In IUGR group, mean birth weight in patients with S/D ratio more than 3 was $2134 \pm 774$ grams while patients with normal doppler study mean birth weight was
$2591 \pm 274$ grams. All three patients with AEDF/REDF in IUGR group delivered macerated still births with mean birth weight of $980 \pm 124$ grams.

Table 5: Effect of umbilical artery velocimetry on neonatal outcome in hypertensive disorder of pregnancy group and IUGR group (gestational age delivery and birth weight) in present study.

\begin{tabular}{|lllllll|}
\hline High risk group & \multicolumn{7}{l}{ Hypertensive disorder of pregnancy } & IUGR & & \\
\hline S/D ratio & $<3$ & $>3$ & AEDF/REDF & $<3$ & A & AEDF/REDF \\
\hline No. of cases & 30 & 21 & 06 & 27 & 06 & 03 \\
\hline $\begin{array}{l}\text { Mean gestational age at } \\
\text { delivery (weeks) }\end{array}$ & $37.6 \pm 2.1$ & $36.4 \pm 2.3$ & $32.5 \pm 0.6$ & $37.0 \pm 1.1$ & $36.0 \pm 2.2$ & $30.5 \pm 0.6$ \\
\hline $\begin{array}{l}\text { Mean birth weight } \\
\text { (grams) }\end{array}$ & $2850.5 \pm 647.5$ & $2275.2 \pm 247.3$ & $1170.2 \pm 381.5$ & $2591.1 \pm 274.5$ & $2134 \pm 774$ & $980.3 \pm 124.6$ \\
\hline
\end{tabular}

Table 6: Obstetrical management in present study.

\begin{tabular}{|llll|}
\hline Index & & Present Study & Percentage \\
\cline { 2 - 4 } & Mean gestational age at delivery in weeks & $35.0 \pm 1.4$ & $38.7 \%$ \\
\cline { 2 - 4 } Labor outcome & Spontaneous delivery & 36 & $38.7 \%$ \\
\cline { 2 - 4 } & Induction of labor & 36 & $09.6 \%$ \\
\cline { 2 - 4 } & Emergency CS & 09 & $12.9 \%$ \\
\cline { 2 - 4 } & Elective CS & 12 & $29.03 \%$ \\
\hline \multirow{5}{*}{ Fetal outcome } & Fetal distress & 27 & $41.9 \%$ \\
& SGA & 39 & $38.7 \%$ \\
\cline { 2 - 4 } & Average Birth weight & $2000.31 \pm 408.23$ & $9.6 \%$ \\
\cline { 2 - 4 } & Spgar Score <7 at 5 min & 36 & $23.8 \%$ \\
\cline { 2 - 4 } & Still Birth & 09 & 20 \\
\hline
\end{tabular}

Table 6 shows at a glance the obstetrical management of the patients studied.

Mean gestational age at delivery was $35.0 \pm 1.4$ weeks in present study. Spontaneous onset of labor was observed in the $38.7 \%$ patients while $9.6 \%$ of the patients underwent emergency cesarean section.

Thirty-nine neonates $(41.9 \%)$ were small for gestational age. Apgar score of less than 7 was observed in thirty-six neonates $(38.7 \%)$ however twenty neonates $(23.8 \%)$ required neonatal intensive care.

Nine still births were seen in present study. Three patients with AEDF/REDF from IUGR group. Six patients from hypertensive group with abnormal doppler velocimetry.

Abnormal S/D ratio was seen in twenty-seven cases of small for gestational age (SGA) and nine cases of appropriate for gestational age (AGA). Sensitivity, specificity, positive predictive value and negative predictive value for small for gestational age was $69.2 \%$, $83.3 \%, 75 \%$, and $78.5 \%$ respectively (Table 7).
Table 7: Predictive value for small for gestational age in present study.

\begin{tabular}{|llll|}
\hline $\begin{array}{l}\text { Birth } \\
\text { weight }\end{array}$ & $\begin{array}{l}\text { Small for } \\
\text { gestational } \\
\text { age (SGA) }\end{array}$ & $\begin{array}{l}\text { Appropriate } \\
\text { for } \\
\text { gestational } \\
\text { age (AGA) }\end{array}$ & Total \\
\hline $\begin{array}{l}\text { Normal } \\
\text { S/D ratio }\end{array}$ & 12 & 45 & 57 \\
\hline $\begin{array}{l}\text { Abnormal } \\
\text { S/D ratio }\end{array}$ & 27 & 09 & 36 \\
\hline Total & 39 & 54 & 93 \\
\hline Sensitivity & Specificity & $\begin{array}{l}\text { Positive } \\
\text { predictive } \\
\text { value }\end{array}$ & $\begin{array}{l}\text { Negative } \\
\text { predictive } \\
\text { value }\end{array}$ \\
\hline $69.2 \%$ & $83.3 \%$ & $75 \%$ & $78.5 \%$ \\
\hline
\end{tabular}

Fetal distress was seen in twenty-seven cases of which eighteen had abnormal doppler velocimetry and nine had normal doppler velocimetry. Sensitivity, specificity, positive predictive value and negative predictive value for fetal distress were $66.6 \%, 81.8 \%, 60 \%$, and $85.7 \%$ respectively (Table 8). 
Table 8: Predictive value for fetal distress in present study.

\begin{tabular}{|llll|}
\hline $\begin{array}{l}\text { Fetal } \\
\text { distress }\end{array}$ & Petal distress & Absent & Total \\
\hline $\begin{array}{l}\text { Normal } \\
\text { S/D ratio }\end{array}$ & 09 & 54 & 63 \\
\hline $\begin{array}{l}\text { Abnormal } \\
\text { S/D ratio }\end{array}$ & 18 & 12 & 30 \\
\hline Total & 27 & 66 & 93 \\
\hline Sensitivity & Specificity & $\begin{array}{l}\text { Positive } \\
\text { predictive } \\
\text { value }\end{array}$ & $\begin{array}{l}\text { Negative } \\
\text { predictive } \\
\text { value }\end{array}$ \\
\hline $66.6 \%$ & $81.8 \%$ & $60 \%$ & $85.7 \%$ \\
\hline
\end{tabular}

\section{DISCUSSION}

A recent development in maternal fetal medicine is the ability to assess the fetoplacental and uteroplacental circulations using doppler ultrasound.

Doppler ultrasonography is changing the ability to map the fetal and maternal component of placental circulation. Doppler ultrasound is useful in obstetric practice for diagnosing intrauterine growth restriction, perinatal asphyxia and fetal distress.

Hypertensive disorders during pregnancy are the most common medical complications encountered in developing countries. They are also most common cause of fetal growth restriction. In most countries hypertensive diseases during pregnancy appear to be the largest single cause of maternal death. According to the world health organization, it is the main cause of perinatal morbidity and mortality.

In umbilical artery velocimetry, the most extensively studied artery in doppler ultrasound is the umbilical artery. Special attention has been given to an association between abnormal doppler velocimetry in the umbilical artery and fetal outcome. The measurement of umbilical artery velocity waveforms appears to offer promise for the clinical assessment of placental function. S/D ratio and PI is extensively studied by many investigators. It has been shown that there is a steady decline in the S/D ratio from 16 weeks to term. ${ }^{2,4}$

In S/D ratio, doppler waveform of the umbilical artery was considered abnormal if $\mathrm{S} / \mathrm{D}$ ratio was equal to or more than 3 or diastolic flow was absent /reversed in the fetuses above the gestational age of 28 weeks. ${ }^{1,5}$

In present study, S/D ratio more than 3 was seen in $29.03 \%$ (twenty one patients from hypertensive disorder of pregnancy group and six patients from intra uterine growth restriction group) and AEDF/REDF seen in $09.67 \%$ (six patients from hypertensive disorder of pregnancy group and three patients from intra uterine growth restriction group) (Table 5).
Arora D et al, and Agarwal S et al, had similar findings, abnormal umbilical artery doppler velocimetry was seen in $32.8 \%$ cases and $28.2 \%$ cases respectively. ${ }^{6,7}$

The mean rate of AEDF/REDF was $7.2 \%$ in well-defined high-risk group (range 1.9 to $10.8 \%$ ). ${ }^{8-10}$

Reverse end diastolic flow (REDF) was present in six patients and absent end-diastolic flow (AEDF) in three patients in this study. Reverse end diastolic flow in umbilical artery was seen in three patient of severe preeclampsia and three patients of severe IUGR. The patients with severe preeclampsia were induced and delivered fresh still birth. Intrapartum fetal distress was noted. The three patients with severe IUGR refused for induction and delivered macerated still born fetuses.

The three patients with severe pre-eclampsia with absent end diastolic flow underwent emergency cesarean section at around 32-33 weeks. The neonatal outcome was good in absent end-diastolic flow patients, but babies were kept in neonatal intensive care unit for low birth weight.

According to the study by Rochelson B et al, and Brar HS et al, AEDF/REDF in umbilical velocimetry was associated with catastrophic perinatal outcome and aggressive perinatal management was advised in these groups of patients. ${ }^{11,12}$ Present study agrees with their suggestion.

Ley $\mathrm{D}$ et al, Kurkinen $\mathrm{M}$ et al, observed higher mortality rates in those fetuses with absent or reversed end diastolic flow. ${ }^{13,14}$

Doppler findings could detect many hours to days before any abnormality, in cardiotocographic tracings. Assessment of EDF (end diastolic flow) is useful because when it is reduced it detect $30 \%$ severe hypoxia, when there is AEDF (absent end diastolic flow) is very worrying sign and detect $50 \%$ severe hypoxia and in case of REDF (reverse end diastolic flow) is ominous which detect $70 \%$ severe hypoxia and fetal death occurs within 7 days. ${ }^{15}$ The pregnancy could be continued even in the presence of AEDF for approximately 1 to 2 weeks with intensive fetal surveillance. This may provide time for administration of steroids to enhance fetal lung maturity and also the extra days may add to the fetal weight. This time also enables for shifting of the patient to tertiary centre where proper neonatal care can be provided. ${ }^{16}$ REDF is a terminal event associated with an extremely high perinatal mortality. ${ }^{16}$ Immediate delivery is advocated when REDF sets in usually with 24 hours of diagnosis and mainly the route of delivery is cesarean section in these pregnancies. ${ }^{17}$ It is reasonable to assume that decreased uteroplacental perfusion during uterine contractions is likely to further jeopardize gaseous exchange in fetuses with pre-existing abnormal umbilical artery velocimetry. ${ }^{18}$ In present study, resistance index (RI), out of 93 patients, thirty-three patients had abnormal RI (Table 4). 
Twenty-four patients were from hypertensive group and nine patients were from intra uterine growth restriction group who had abnormal RI.

Pulsatility index (PI), in present study, PI more than 1 was considered abnormal. Thirty-nine patients had abnormal PI (Table 4). All patients of abnormal PI had abnormal S/D and showed similar outcome.

In study by Mendez MA et al, it was seen that abnormal RI of umbilical artery and altered PI of umbilical artery were associated with pre-eclampsia. ${ }^{19}$

The association between abnormal umbilical artery doppler velocimetry and adverse pregnancy outcomes has been investigated widely. ${ }^{12,20}$ Many reports have shown statistically significant relation between increased fetoplacental resistance, as estimated by either the resistance index (RI) or systolic-diastolic ratio (S/D), and the later development of either pre-eclampsia or fetal growth restriction. $^{21,22}$

In gestational age at delivery, present study showed mean gestational age at delivery was $35.0 \pm 1.4$ weeks (Table 6).

Patients with hypertensive disorders of pregnancy with normal velocimetry delivered at $37.6 \pm 2.1$ weeks while those with abnormal velocimetry delivered at 36.4 \pm 2.3 weeks. Patients with intrauterine restriction with abnormal doppler delivered at 36.0 \pm 2.2 weeks (Table 5).

Dempster $\mathbf{J}$ et al, did not find any statistically significant difference of gestational age at delivery. ${ }^{23}$

Mean gestational age at delivery of the patients with absent or reverse diastolic flow was $31.5 \pm 0.6$ weeks in present study.
Table 9: Mode of delivery in various studies.

\begin{tabular}{|c|c|c|c|}
\hline Study & $\begin{array}{l}\text { Induction } \\
\text { of labor }\end{array}$ & $\begin{array}{l}\text { Elective } \\
\text { cesarean } \\
\text { section }\end{array}$ & $\begin{array}{l}\text { Emergency } \\
\text { cesarean } \\
\text { section }\end{array}$ \\
\hline Haley $\mathrm{J}$ et $\mathrm{al}^{8}$ & $23.28 \%$ & $9.5 \%$ & $12.3 \%$ \\
\hline $\begin{array}{l}\text { Trudinger BJ } \\
\text { et } \mathrm{al}^{26}\end{array}$ & 44.88 & $10.6 \%$ & $12.2 \%$ \\
\hline Westergaard $^{27}$ & $28.2 \%$ & $12.0 \%$ & $12.3 \%$ \\
\hline Present study & $38.7 \%$ & $9.6 \%$ & $12.9 \%$ \\
\hline
\end{tabular}

In the study of Brar HS et al, Zelop CM et al, Young Ji B et al, gestational age at delivery in patients with reverse end diastolic flow matches with present study. ${ }^{12,24,25}$

Mode of delivery in present study, spontaneous onset of labor was observed in the $38.7 \%$ patients, induction of labor was done in $38.7 \%$ of the patients. Emergency cesarean section was carried out in $12.9 \%$ of cases while $9.6 \%$ cases underwent elective cesarean section (Table 6).

Rate of cesarean section in different studies were similar to the present study (Table 9). ${ }^{8,26,27}$

Birth weight in the present study, mean birth weight of babies was 2000.31 \pm 408.23 grams (Table 6).

Mean birth weight was $2275 \pm 247$ grams in patients with abnormal doppler velocimetry in hypertensive disorder group. While patients with IUGR group, mean birth weight with abnormal doppler was $2134 \pm 774$ grams (Table 5).

All nine babies with AEDF/REDF were small for gestational age. This finding is similar to the study of Brar HS et al. ${ }^{12}$

Table 10: Predictive values for small for gestational age babies in various studies.

\begin{tabular}{|lllll|}
\hline Study & Sensitivity & Specificity & Positive predictive value & Negative predictive value \\
\hline Fleischer et al $^{22}$ & 78 & 83 & 49 & 95 \\
\hline Divon et al $^{28}$ & 49 & 94 & 81 & 77 \\
\hline Chanprapaph et al $^{29}$ & 53 & 78 & 74 & 65 \\
\hline Present study & 69.2 & 83.2 & 75 & 78.5 \\
\hline
\end{tabular}

In present study, thirty-nine babies were small for gestational age with positive predictive value of $75 \%$ (Table 7). Table 10 shows predictive values for small for gestational age babies in various studies. ${ }^{22,28,29}$

Fetal distress in present study, 18 patients had fetal distress with abnormal doppler velocimetry (Table 8).
Rochelson B et al, in a study of 54 pregnancies producing growth restricted infants observed fetal distress in 20 of $38(53 \%)$ with abnormal umbilical artery S/D ratio. ${ }^{1}$

Brar HS et al, in a study of 8 pregnancies with reverse end diastolic flow velocity observed fetal distress during labor in 6 of the 8 cases $(75 \%){ }^{12}$ 
Table 11: Predictive values for fetal distress in various studies.

\begin{tabular}{|llllll|}
\hline Study & Fetal distress $(\%)$ & Sensitivity & Specificity & Predictive value & Positive \\
\hline Rochelson $^{11}$ & 13 & 57 & 72 & 24 & 92 \\
\hline Berkowitz $^{30}$ & 12 & 43 & 81 & 24 & 91 \\
\hline Weiner $^{31}$ & 27 & 53 & 76 & 45 & 81 \\
\hline Present study & 60 & 66.6 & 88 & 60 & 85.7 \\
\hline
\end{tabular}

Three studies of selected high-risk pregnancy have data on the predictive value of doppler velocimetry for fetal distress during labor (Table 11). ${ }^{11,30,31}$

Apgar score has traditionally been used as a measure of fetal outcome. In the present study, low Apgar scores were seen in $38.7 \%$ (Table 6).

A number of studies have examined the relationship between fetal blood flow velocity and Apgar score less than 7 at 5 minutes. Rochelson $\mathrm{B}$ et al, did not find significant association of abnormal umbilical artery S/D ratio and low Apgar scores. ${ }^{11}$ However, in contrast Brar HS et al, and Seyam YS et al, found a significant association of abnormal umbilical artery S/D ratio with a low Apgar score. ${ }^{32,33}$

In fetal outcome, present study shows 3 macerated still births $(33.3 \%)$ out of 9 in patient with REDF. Brar HS et al, in their study observed, $33.3 \%$ still births. ${ }^{12}$

About $23.8 \%$ of the neonates were kept in neonatal intensive care unit. These findings match the studies of James Ducey and Rajan R et al. ${ }^{34,35}$

In present study, $29.03 \%$ cases were small for gestational age with abnormal umbilical artery doppler.

Rochelson B, Divon MY, Kofinas AD, Maulik D et al, all observed poor perinatal outcome in small for gestational age babies with abnormal umbilical artery Doppler studies. ${ }^{1,5,36,37}$

Meta-analysis of randomized controlled trials by Neilson JP et al, recommend that incorporation of umbilical artery doppler waveform analysis into management protocols for intrauterine growth restricted fetuses considerably reduces perinatal moratality. ${ }^{38}$

\section{CONCLUSION}

From present study, author can conclude that doppler velocimetry can provide important information about umbilical circulation and fetal wellbeing. Study of the umbilical doppler velocimetry is more useful in management of high-risk pregnancy. Doppler velocimetry can be useful prenatal test for the patients of hypertensive disorder of pregnancy and IUGR. Actual risk involved to the fetus or the mother in case of hypertensive disorder of pregnancy could be sorted out based on the blood flow velocity pattern and management could be advocated depending on the nature and the extent of the risk involved.

Early intervention needed in patients with AEDF/REDF, as the perinatal deaths are very high in this group. Perinatal morbidity and mortality can be reduced by fetal surveillance with timely doppler velocimetry study.

The umbilical doppler waveform serves as a placental function that gives us diagnostic and prognostic information.

\section{Funding: No funding sources \\ Conflict of interest: None declared \\ Ethical approval: The study was approved by the Institutional Ethics Committee}

\section{REFERENCES}

1. Rochelson BL, Schulman H, Fleischer A, Farmakides G, Bracero L, Ducey J, et al. The clinical significance of doppler umbilical artery velocimetry in the small for gestational age fetus. Am J Obs Gynecol. 1987;156(5):1223-6.

2. Trudinger BJ, Giles WB, Cook CM. Flow velocity waveforms in the maternal uteroplacental and fetal umbilical placental circulations. Am J Obs Gynecol. 1985;152(2):155-63.

3. O'Neill AM, Burd ID, Sabogal JC, Seamon JS, Weiner S. Doppler Ultrasound in obstetrics and Gynecology. 17th ed. 2005;98-112.

4. Schulman H, Fleischer A. Umbilical velocity wave ratio in human pregnancy. Am J Obstet Gynecol. 1984;148:985-9.

5. Divon MY, Ferber A. Doppler evaluation of fetus. Cinlical Obstet Gynecol. 2002;45:1015-25.

6. Arora D, Desai SK, Sheth PN, Kania P. Significance of umbilical artery velocimetry in perinatal outcome of growth restricted fetuses. J Obstet Gynecol. 2005;55(2):138-143.

7. Agrawal S, Das V, Agarwal A, Pandey A. Fetal Doppler for prediction of adverse perinatal outcome in preeclampsia in a low resource setting. Int $\mathbf{J}$ Reprod Contracept Obstet Gynecol. 2016;5:3439-43. 
8. Haley J, Tuffnell DJ, Johnson N. Randomised controlled trial of cardiotocography versus umbilical artery doppler in the management of small for gestational age fetuses. Brit J Obstet Gynaecol. 1997;104:431-5.

9. Pattinson RC, Norman K, Odendaal HJ. The role of doppler velocimetry in the management of high-risk pregnancies. Brit J Obstet Gynaecol. 1994;101:11420.

10. Johnstone FD, Prescott R, Hoskins P, Greer IA, McGlew T, Compton M. The effect of introduction of umbilical Doppler recordings to obstetric practice. Br J Obstet Gynaecol. 1993;100:733-41.

11. Rochelson B, Schulman H, Farmakides G, Bracero L, Ducey J, Fleischer A, et al. The significance of absent end diastolic velocity in umbilical artery waveforms. Am J Obstet Gynecol. 1987;156(5):1213-8.

12. Brar HS, Lowrence PD. Reverse end diastolic flow velocity on umbilical artery velocimetry in high risk pregnancies: an ominous finding with adverse pregnancy outcome. Am J Obstet Gynecol. 1988;159:559-61.

13. Ley D, Tideman E, Laurin J, Bjerre I, Marsal K. Abnormal fetal aortic velocity waveform and intellectual function at 7 years of age. Ultrasound Obstet Gynecol. 1996;8:160-5.

14. Kurkinen-Raty M, Kivela A, Jouppila P. The clinical significance of an absent end-diastolic velocity in the umbilical artery detected before the 34th week of pregnancy. Acta Obstet Gynecol Scand. 1997;76:398-404.

15. GRIT Study group. When do obstetricians recommend delivery for a high-risk preterm growthretarded fetus? Euro J Obstet Gynecol Reprod Biol. 1996;67:121-6.

16. Tyrrell SN, Lilford RJ, Macdonald HN, Nelson EJ, Porter J, Gupta JK. Randomized comparison of routine vs. highly selective use of Doppler ultrasound and biophysical scoring to investigate high risk pregnancies. Brit J Obstet Gynecol. 1990;97:909-16.

17. Gezginc K, Acar A, Peru H, Karatoyli R, Colic C, Capar M. How to manage intrauterine growth restriction associated with severe preeclampsia at 2834 weeks of gestation? Eur J Gen Med. 2008;5(4):212-5.

18. Maulik D, Mundy D, Heitmann E, Maulik D. Umbilical artery Doppler in the assessment of fetal growth restriction. Clin Perinatol. 2011;38:65-82.

19. Mendez MA, Gayta MV, Flores R. Doppler ultrasound evaluation in preeclampsia. BMC Res Notes. 2013;19:477.

20. Tyrrell S, Obaid AH, Lilfora RJ. Umbilical artery Doppler velocimetry as a predictor of fetal hypoxia and acidosis at birth. Obstet Gynecol. 1989;74:332-7.

21. Fleischer A, Schulman H, Farmakides G, Bracero L, Randolph BG. Umbilical artery velocity waveforms and intrauterine growth retardation. Am J Obstet Gynecol. 1985;151:502-5.
22. Trudinger BJ, Giles WB, Cook CM, Bombardieri J Collins LE. Fetal umbilical artery flow velocity wave forms and placental resistance clinical significance. Brit J Obstet Gynaecol. 1985;92:23-30.

23. Dempster J,Mires GJ, Patel N, DJ Taylor. Umbilical artery velocity waveforms: poor association with small for gestation age babies. Brit J Obs Gynecol. 1989;96(6):692-6.

24. Zelop CM, Richardson DK, Heffner LJ. Outcomes of severely abnormal umbilical artery Doppler velocimetry in structurally normal singleton fetuses. Obstet Gynecol. 1996;87:434-8.

25. Byun YJ, Kim HS, Yang JI, Kim JH, Kim HY, Chang SJ. Umbilical artery doppler study as a predictive marker of perinatal outcome in preterm small for gestational age infants. Yonsei Med J. 2009;50(1):39-44.

26. Trudinger BJ, Giles WB, Cook CM. Umbilical artery flow velocity in high risk pregnancy. Lancet. 1987;329:188-190.

27. Westergaard HB, J. Langhoff-Roos G. Lingman K. Marsal: a critical appraisal of the use of umbilical artery doppler ultrasound in high-risk pregnancies: use of meta-analyses in evidence-based obstetrics. Ultrasound Obstet Gynecol. 2001;17:466-76.

28. Michael DY, Jeffery J. Umbilical artery Doppler velocimetry. Clinical utility in high risk pregnancy. Am J Obstet Gynecol. 1996;174(4):10-4.

29. Chanprapaph P, Tongsong T, Siriaree S. Validity of antenatal diagnosis of intrauterine growth restriction by umbilical doppler waveform index. J Med Assoc Thailand. 2004;87(5):492-6.

30. Berkowitz GS, Chikara U, J Rosenberg. Sonographic estimation of fetal weight and Doppler analysis of umbilical artery velocimetry in the prediction of intrauterine growth retardation: a prospective study. Am J Obstet Gynecol. 1988;158:1149-53.

31. Weiner Z, Farmakides G, Schulman H, Lopresti S, Schneider E. Surveillance of growth-retarded fetuses with computerized fetal heart rate monitoring combined with doppler velocimetry of the umbilical and uterine arteries. J Repro Med. 1996;41(2):112-8.

32. Brar HS, Lowrence PD. Antepartum improvement of abnormal umbilical artery velocimetry: Does it occur?. Am J Obstet Gynecol. 1988;160:36-9.

33. Seyam YS, Al-Mahmeid MS, Al-Tamimi HK. Umbilical artery Doppler flow velocimetry in intrauterine growth restriction and its relation to perinatal outcome. Int $\mathbf{J}$ Gynecol Obs. 2002;77(2):131-7.

34. James Ducey. Velocity waveform in hypertensive disease. Clin Obs Gynecol. 1989:32(4);679-86.

35. Rajan R, Vasantha R, Jaya S. Classification of PIH based on Doppler flow velocimetry studies. Ind $\mathrm{J}$ Obstet Gynecol. 1994:495-501.

36. Kofinas AD, Penry M, Nelson LH, Meis PJ, Swain M. Uterine and umbilical artery flow velocity waveform analysis in pregnancies complicated by chronic hypertension or preeclampsia. South Med J. 1990;83:150-5. 
37. Maulik D. Doppler ultrasound velocimetry for fetal surveillance. Clini Obstet Gynecol. 1995;38:91-111.

38. Neilson JP, Alfirevic Z. Doppler ultrasound for fetal assessment in high risk pregnancies. Cochrane Database Syst Rev. 2000;2:CD000073.
Cite this article as: Suryavanshi MR, Katakdhond SS. Efficacy of doppler velocimetry of the umbilical artery in the defined high-risk groups to determine the fetal outcome. Int J Reprod Contracept Obstet Gynecol 2019;8:1724-32. 